Journal of Clinical Investigation

Vol. 42, No. 2, 1963

\title{
THE INTERNAL ANAL SPHINCTER RESPONSE: MANOMETRIC STUDIES ON ITS NORMAL PHYSIOLOGY, NEURAL PATHWAYS, AND ALTERATION IN BOWEL DISORDERS *
}

\author{
BY MARVIN M. SCHUSTER, THOMAS R. HENDRIX, AND \\ ALBERT I. MENDELOFF \\ (From the Department of Medicine, The Johns Hopkins University School of Medicine, \\ Baltimore, $M d$.)
}

(Submitted for publication July 6, 1962; accepted October 18, 1962)

Manometric recordings of lower bowel motility have been difficult to interpret because 1) this segment frequently displays no spontaneous activity for periods as long as 6 hours $(1), 2$ ) attempts to stimulate normal activity have been met with inconsistent results (2-4), and 3) the activity observed has not been clearly related to this segment's primary function, defecation (2-7).

We have described previously (8) an internal anal sphincteric response that can be elicited at will, is regularly reproducible, and is analogous to the physiological concomitants of defecation. This response is essentially that reported in 1877 by Gowers, who found that insufflation of air into the rectum produces relaxation of the internal anal sphincter (9). Very few investigations of this response, however, have subsequently been carried out.

This investigation was designed to define in the human 1) the normal physiology of the sphincter response, 2) the neural pathways involved, and 3 ) the effect of various disorders of bowel function upon this response.

\section{MATERIAL AND METHODS}

Sphincteric function was examined in the following groups of patients (Table I) : $a$ ) normal controls; $b$ ) paraplegics with complete spinal cord transection at levels ranging from $\mathrm{C}-7$ to $\mathrm{T}-2 ; c$ ) biopsy-proven cases of Hirschsprung's disease before surgery; $d$ ) patients with Hirschsprung's disease who were asymptomatic after proctosigmoidectomy ; $e$ ) patients with Hirschsprung's disease in whom fecal incontinence appeared after proctosigmoidectomy; $f$ ) patients with functional megacolon ("pseudo-Hirschsprung's disease") and fecal incontinence; $g$ ) patients who had undergone partial sigmoidectomy and partial proctectomy, the lower rectum being

* Work suported in part by training grant 2A-5095 of the National Institute for Arthritis and Metabolic Diseases, Bethesda, Md. left intact; $h)$ a group of patients with various disturbances of bowel function, including the irritable colon syndrome, diverticulitis, diabetic autonomic diarrhea, megacolon secondary to intermittent volvulus, and posthemorrhoidectomy diarrhea. The oldest patient studied was 77 years old, the youngest, 10 weeks.

The apparatus used to measure sphincter function consisted of a balloon assembly attached via polyethylene tubes to Sanborn differential pressure transducers and a direct-writing electrical recorder. The tubes had an external diameter of $6 \mathrm{~mm}$ and an internal diameter of 4 $\mathrm{mm}$; although somewhat flexible, they were rigid enough not to double on themselves in the rectum. The two cephalad tubes were taped together in tandem so that their tips were always $10 \mathrm{~cm}$ apart. Miller-Abbott balloons $4.5 \mathrm{~cm}$ long were attached to the end of the tubes as illustrated in Figure 1A. When filled without stretching, the balloons contained $50 \mathrm{ml}$ air and were $4.0 \mathrm{~cm}$ in diameter. During recording in the resting stage, the balloons were kept inflated with $7 \mathrm{ml}$ air to keep their walls slightly away from the side openings of the tube. This volume of air did not stimulate colonic motility in any of the patients, thus confirming the impression that in routine studies of colonic motility, tracings obtained with a small balloon do not differ appreciably from those transmitted via fluid-filled open-tipped catheters (10). The caudad balloon was so constructed that when distended with $17 \mathrm{ml}$ air, it was $4 \mathrm{~cm}$ in diameter and 2.5 cm long.

No premedication was administered, and no laxatives or enemas were given to normal subjects. Eight patients received hypertonic phosphate enemas to facilitate recording when impaction or watery stool was present. The recordings from patients who received such enemas were similar to those in patients who required none. This has also been the experience reported by others in routine studies of colon motility (2). With the patient in the knee-chest position, the tubes were passed through the proctoscope so that the cephalad balloon lay in the rectosigmoid colon with the tip of the tube at 22 to 25 $\mathrm{cm}$, while the middle balloon lay in the rectum with its tip $10 \mathrm{~cm}$ caudad to the cephalad balloon. The third tube, also in the rectum, was unattached to the other two. The proctoscope was then withdrawn over the tubes. Finally, the caudad balloon was pulled against the internal anal sphincter and held there snugly by a string 
TABLE I

Patients

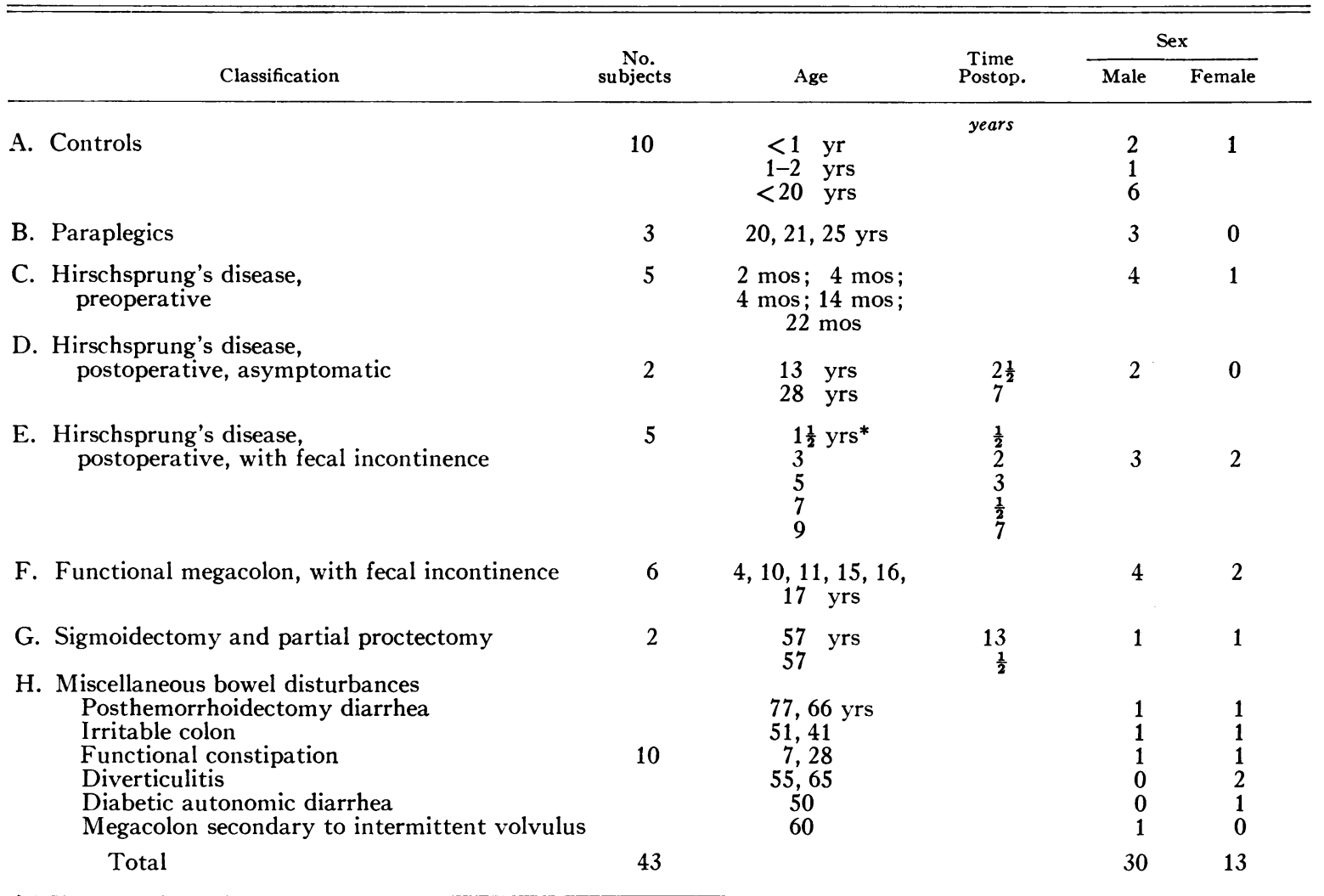

* This patient is grouped among those with incontinence because she had incessant dribbling of stool and severely macerated buttocks.

from the tube to a pulley system with a 200-g counterweight (Figure 1B). Accurate placement against the sphincter was indicated by a rise in pressure in the tracing from the caudad balloon as it was pulled into the anal canal (Figure 2). The mean increase in pressure upon entry into the anal canal was $12 \mathrm{~mm} \mathrm{Hg}$, ranging from 5 to $22 \mathrm{~mm} \mathrm{Hg}$. The balloon was not visible at the anal orifice under these circumstances. During the test, the subject was placed in the left lateral semiprone position, and was unable to view the actual recording (Figure 1B). Subjects were informed simply that colonic motility was being studied by the use of plastic tubes. Subjective sensations were recorded as reported. A pneumograph monitored respiration and body movements.

After a short period of recording in the resting state, one of the two cephalad balloons was rapidly inflated with $50 \mathrm{ml}$ air and quickly deflated, by a hand syringe attached to a 3-way stopcock. During this procedure, which required about 2.5 seconds, recording from the distending balloon was interrupted. After this, the other cephalad balloon was inflated momentarily in similar fashion. The technic of transient inflation was in some instances compared with prolonged distension, during which the balloon was inflated for 30 to 90 seconds.
In infants, only two balloons were used and were inserted without use of the proctoscope. The cephalad tip was inserted to $10 \mathrm{~cm}$ while the caudad balloon was held against the sphincter by manual traction. Tubes used for infants had an external diameter of $3 \mathrm{~mm}$ and an internal diameter of $1.5 \mathrm{~mm}$. The sphincteric balloon, when distended with $15 \mathrm{ml}$ air, assumed a diameter of 3 $\mathrm{cm}$ and a length of $2.5 \mathrm{~cm}$. Infants were held supine during the test with the legs flexed at hip and knee.

\section{RESULTS}

Table II summarizes the results for all groups studied.

A. Normal subjects. In all, distension of the rectal or rectosigmoid balloon produced relaxation of the internal anal sphincter, as manifested by a transient fall in pressure within the caudad balloon (Figure 3, A-D). The mean duration of this relaxation was 12.8 seconds, with a range of 4 to 18 seconds. This same range of variation among subjects was also seen in a single subject. 


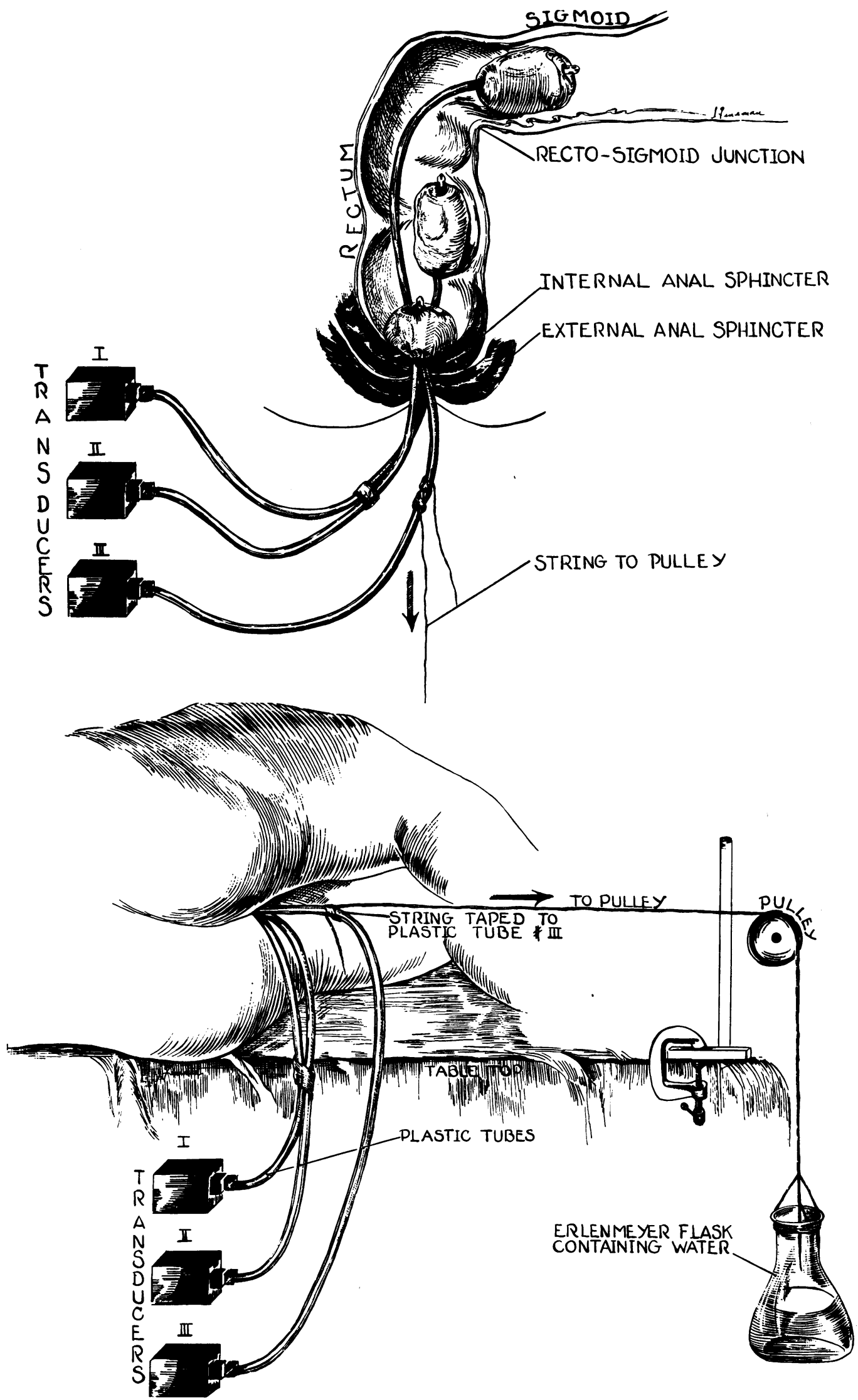

Fig. 1. Schematic diagram of Recording technic. A. Balloons in situ without weight attached to caudad tube. B. Counterweight traction applied to caudad tube. 
TABLE II

Sphincter response

\begin{tabular}{|c|c|c|c|}
\hline Classification & Positive & Negative & Abnormal \\
\hline A. Controls & 10 & 0 & 0 \\
\hline B. Paraplegics & 3 & 0 & 0 \\
\hline $\begin{array}{l}\text { C. Hirschsprung's disease, } \\
\text { preoperative }\end{array}$ & 5 & 0 & 0 \\
\hline $\begin{array}{l}\text { D. Hirschsprung's disease, } \\
\text { postoperative, asymptomatic }\end{array}$ & 0 & 2 & 0 \\
\hline $\begin{array}{l}\text { E. Hirschsprung's disease, } \\
\text { postoperative, with fecal } \\
\text { incontinence }\end{array}$ & 0 & 0 & $5^{*}$ \\
\hline $\begin{array}{l}\text { F. Functional megacolon, } \\
\text { with fecal incontinence }\end{array}$ & 6 & 0 & 0 \\
\hline $\begin{array}{l}\text { G. Partial proctectomy } \\
\text { 1. Distension cephalad to } \\
\text { anastomosis }\end{array}$ & 0 & 2 & 0 \\
\hline $\begin{array}{l}\text { 2. Distension caudad to } \\
\text { anastomosis }\end{array}$ & 2 & 0 & 0 \\
\hline H. Miscellaneous bowel disturbances & 10 & 0 & 0 \\
\hline Total & 36 & 4 & 5 \\
\hline
\end{tabular}

* An abnormal sphincter response was also found in a 7-year-old boy with functional megacolon who had undergone a proctosigmoidectomy and still had encopresis 3 years postoperatively. An additional patient, age 5 months, had an abnormal response shortly after proctosigmoidectomy at a time when fecal dribbling was prominent. An incomplete resection of aganglionic segment had been performed so that aganglionic colon was anastomosed to anus.

Failure of sphincteric relaxation occurred only 5 times in 97 distensions in these subjects (and only 8 times in 600 distensions in all subjects without sphincter abnormality). After prolonged distension, the sphincter rapidly regained its tone even though rectal distension was maintained (Figure 4A). Occasionally the sphincter maintained a state of partial relaxation as long as the rectum remained distended (Figure 4B).

Voluntary contraction of the external anal

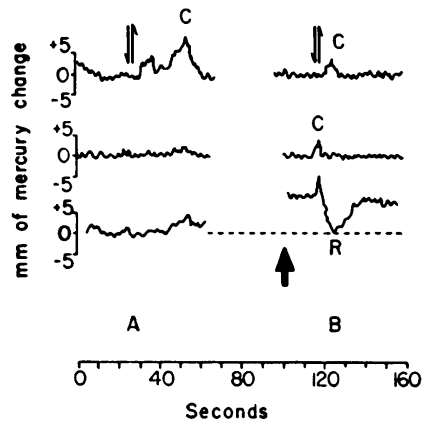

Fig. 2

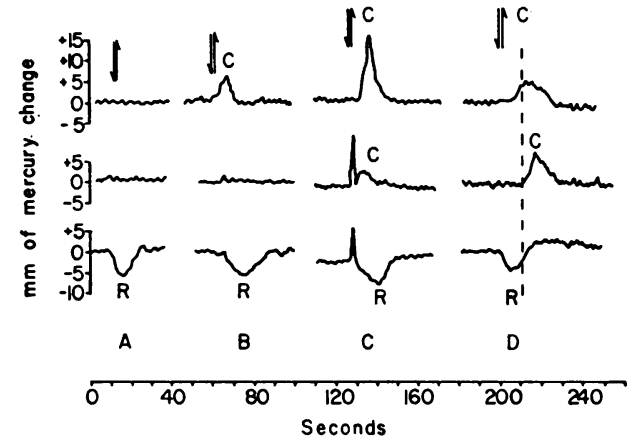

Fig. 3

Fig. 2. High PRESSURe zone in internal anal sphincter. In this and in subsequent figures, Roman numerals refer to location of recording balloons as indicated in the drawing in Figure 3. A downward arrow indicates inflation and an upward arrow deflation of the distending balloon. " $C$ " designates contraction around a recording balloon. " $R$ " represents sphincteric relaxation. A. Distension of the rectosigmoid colon (arrows) fails to produce pressure decrease in caudad balloon (III) which lies immediately cephalad to the sphincter. B. Rise in baseline (heavy arrow) appears when the caudad balloon is pulled into the sphincter. Distension (arrows) now produces sphincteric relaxation.

Fig. 3. FOUR TYPES OF COlONIC RESPONSE IN NORMAL SUBJECTS. A. No colonic contractions and sphincter relaxes normally (R), in 77 per cent of distensions. B. Colonic contraction around distending balloon (C), in 16 per cent. C. Synchronous contraction (C) in rectosigmoid colon (I) and rectum (III), in 13 per cent. D. Progressive wave of contraction (C) from rectosigmoid colon (I) to rectum (II), in 4 per cent of distensions. 


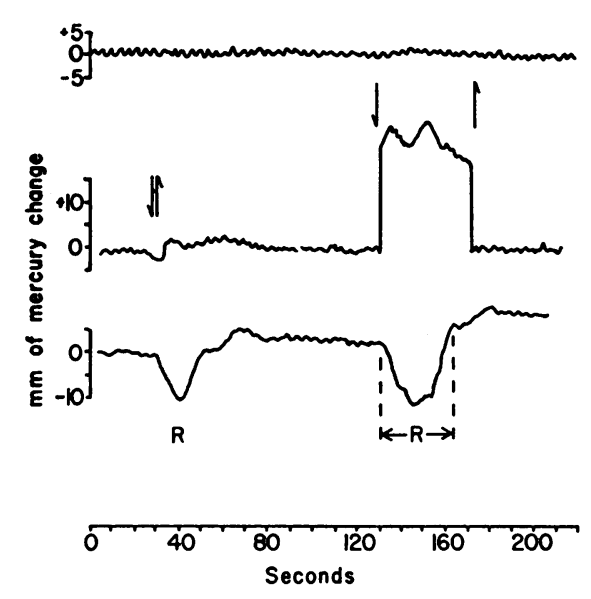

Fig. $4(A)$

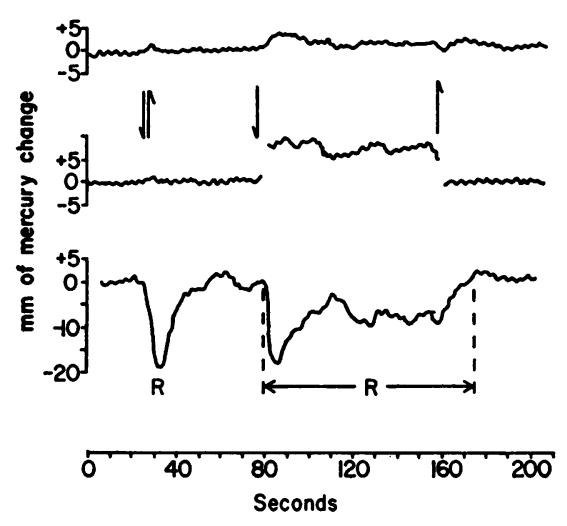

Fig. 4 (B)

Fig. 4. Transient distension compared with prolonged rectal distension. A. Prolonged distension (arrows) produces sphincter relaxation of longer duration $(\leftarrow R \rightarrow)$ than normal. Sphincter regains tone despite continued rectal distension. B. Here the sphincter remains relaxed $(\leftarrow R \rightarrow)$ until distension is released.

sphincter and levatores ani produced a rise in pressure in the sphincteric balloon; it was not possible, however, to inhibit internal anal sphincter relaxation by voluntary effort (Figure 5 ). There was no subjective awareness of changes in sphincter tone. Age did not appear to affect the response. When spontaneous motility was present in the colon, it was immediately inhibited by rectal balloon distension.

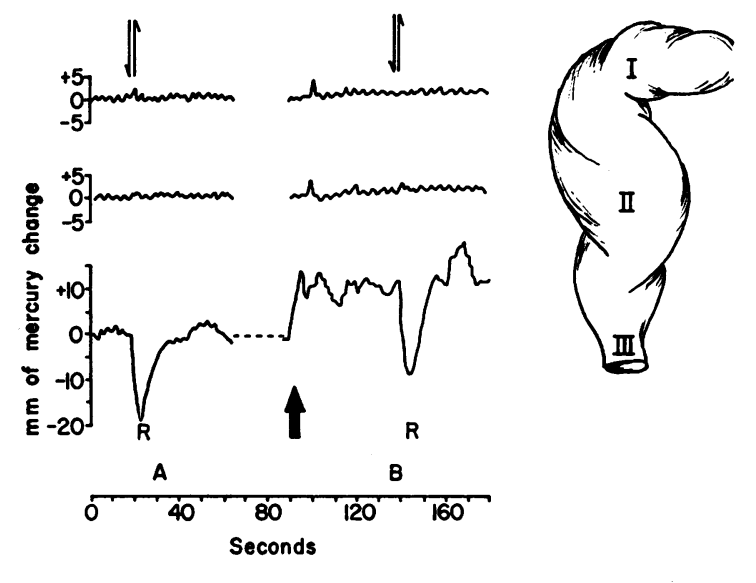

Fig. 5

Fig. 5. FaIlure of voluntary inhibition to inFLUENCE INTERNAL ANAL SPHINCTER RESPONSE. A. Normal sphincter relaxation (R). B. Voluntary contraction of external anal sphincter and levatores ani (heavy arrow) results in elevation of baseline in caudad balloon (III), but fails to inhibit relaxation of internal sphincter (R).
Four types of colonic response were elicited, and are seen in Fig 3 as $\mathrm{A}, \mathrm{B}, \mathrm{C}$, and D. In 77 per cent of the distensions, no pressure change occurred in either the rectal or rectosigmoid balloon (Figure 3, A). In 16 per cent, there was a contraction around the distending balloon (Figure $3, \mathrm{~B}$ ), and in 13 per cent, synchronous contractions were seen with simultaneous pressure elevations in both cephalad balloons (Figure 3, C). In 9 per cent, coordinated contractions of peristaltic type were recorded in the distending balloon in the rectosigmoid colon and the recording balloon in the rectum (Figure 3, D). In all instances, the pressure decrease in the sphincteric balloon (i.e., sphincteric relaxation) appeared simultaneously with distension of the rectosigmoid balloon. When peristalsis was present in the colon, sphincteric relaxation preceded arrival of the wave of contraction in the rectal balloon; sphincteric tonus often had returned to normal by the time the wave of contraction was recorded in the rectum.

B. Paraplegic subjects. In the three patients tested, the sphincter responded in normal fashion. None of these patients had voluntary control of defecation and each suffered rare episodes of fecal incontinence. For years, all had been taking enemas regularly in order to produce automatic defecation. Perianal scratching in these patients failed to produce reflex contraction of the external anal sphincter ("anal reflex"). 
C. Patients with Hirschsprung's disease studied preoperatively. Five patients were studied. All exhibited the normal sphincter relaxation pattern.

D. Patients with Hirschsprung's disease studied postoperatively who were asymptomatic after proctosigmoidectomy (Swenson procedure). Two pa- tients, who had normal bowel habits and no fecal incontinence after the pull-through procedure, showed no sphincter relaxation or change in tone after rectal distension.

E. Patients with Hirschsprung's disease who developed incontinence following proctosigmoidec-
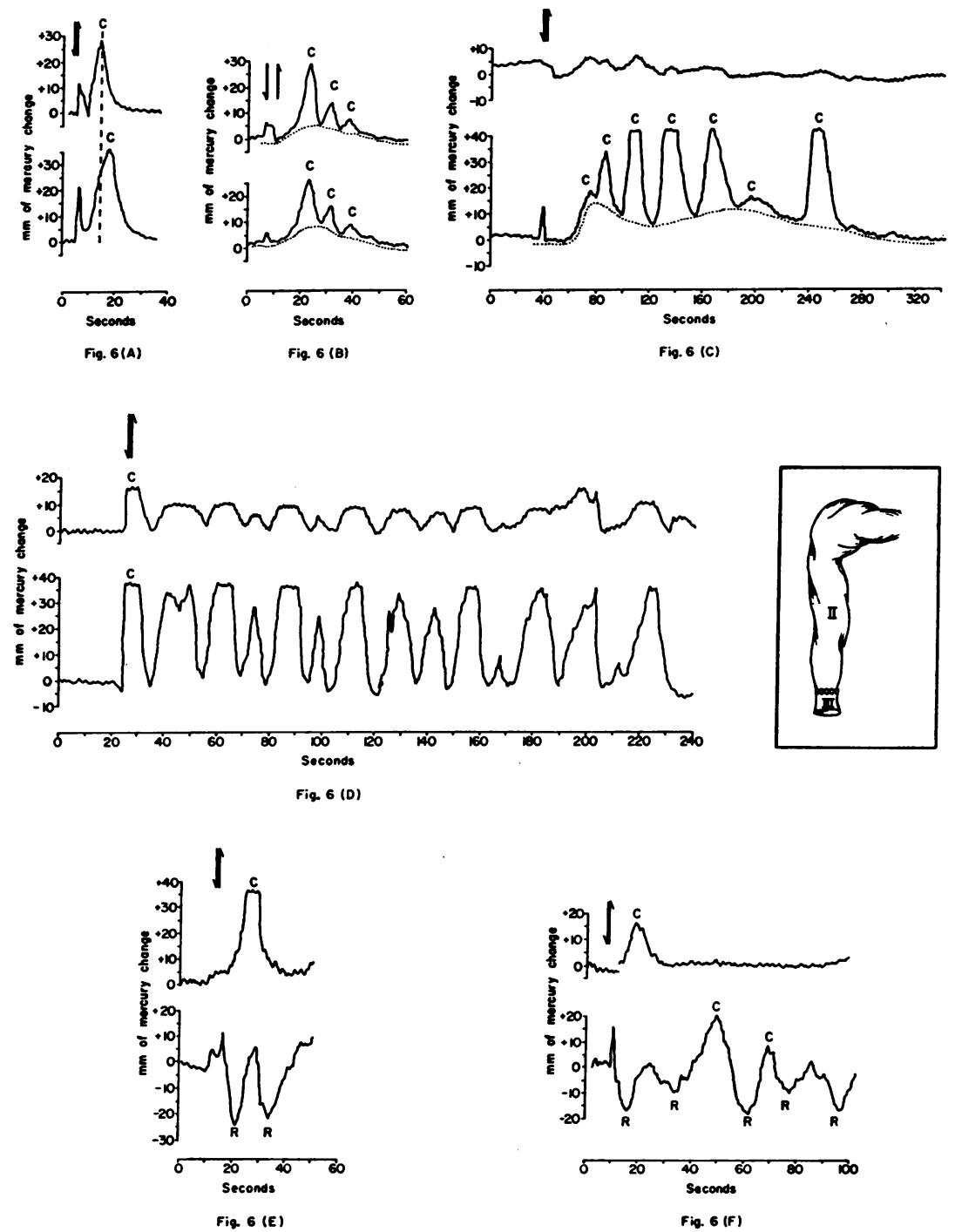

Fig. 6. Abnormal Responses in patients With incontinence following Proctosigmoidectomy. A. Progressive wave of contraction (C) proceeds from colon (II) to sphincter (III). Sphincter fails to relax. B. Colonic distension produces synchronous waves of contraction (C) in rectal (II) and sphincter (III) balloon superimposed upon increase in baseline tonus (broken line). Sphincter fails to relax. C. Transient distension of the colon produces multiple spasmodic contractions (C) around the sphincter balloon superimposed upon an increase in tonus, manifested by elevated baseline (broken line). Sphincter fails to relax. D. Multiple spasmodic contractions (C) simultaneously in colonic (II) and sphincter balloon (III) after a single transient distension (arrows). Sphincter fails to relax. $\mathrm{E}$ and $\mathrm{F}$. Multiple sphincteric relaxations appear with a single distension of the colon. 


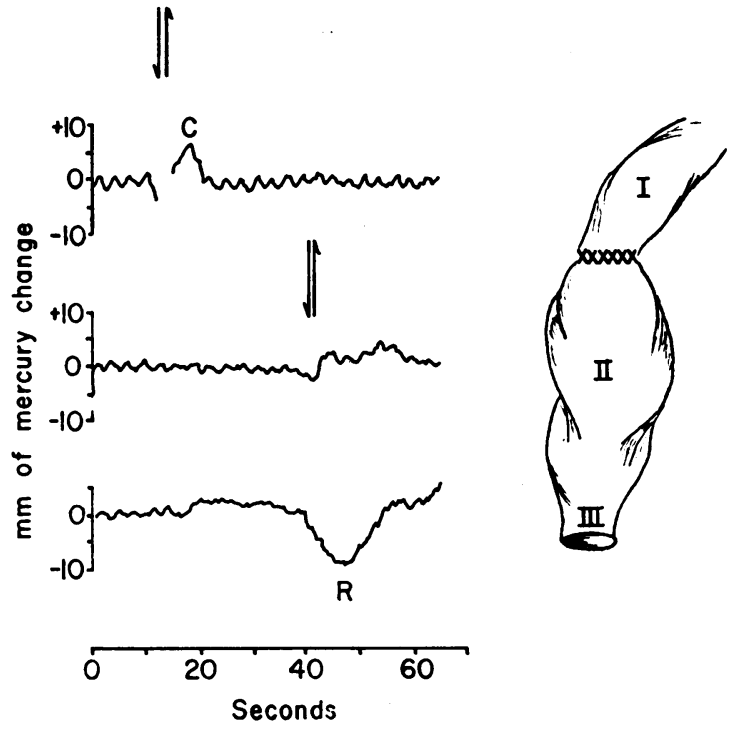

Fig. 7

Fig. 7. Partial proctosigmoidectomy. Distension of balloon above anastomosis (I) fails to produce sphincter relaxation. Distension of the intact rectum (II) produces normal sphincter response $(\mathrm{R})$.

tomy. Of the five subjects, all showed abnormal responses. In four this abnormality consisted of repetitive contractions recorded in the sphincteric balloon when the rectum was distended above (Figure $6 \mathrm{~A}-\mathrm{D}$ ). One patient exhibited multiple sphincteric relaxations in response to a single distension (Figure $6 \mathrm{E}, \mathrm{F}$ ).

F. Patients with functional megacolon and encopresis. All had normal sphincteric responses.

G. Patients who had undergone partial proctectomy and sigmoidectomy (one for sigmoid carcinoma and one for "acquired megacolon"). Both patients had anastomosis of the descending colon to the mid-rectum. Both showed a normal sphincteric response when distension was applied to the intact lower rectum caudad to the anastomosis, whereas distension cephalad to the anastomosis had no effect on sphincteric tone (Figure 7).

H. Patients with various bowel disorders. None had any symptoms related to sphincteric dysfunction, and all had normal responses.

DISCUSSION

A. Results. Rapid balloon distension of the rectum has been shown to produce relaxation of the internal anal sphincter. In our experiments, as in the classic studies by Denny-Brown on the nervous control of defecation (11), a normal response in patients with spinal cord transection indicates that centers higher than the spinal cord are not required for the mediation of this response. A normal response was, however, also found in patients with aganglionosis coli (Hirschsprung's disease). Thus the intramural ganglion cells of the myenteric plexus are not required either in the transmission of impulses, as has been suggested (11-16), or in the effector organ (the internal anal sphincter) (12-14), since myenteric ganglion cells are absent from this organ as well as from the rectum in Hirschsprung's disease (13. 14, 16-23). These findings contradict the generally accepted concepts that an intact myenteric plexus is essential for internal anal sphincteric relaxation $(12,16)$, and that the internal anal sphincter, because it is spastic, fails to relax in Hirschsprung's disease (13-15, 17, 18, 22, 24). Denny-Brown suggested in his monograph that "the nervous mechanism for the 'reflex' reaction appears to be related solely to the peripheral nervous plexus. . . . The mechanism of postural tone of sphincter ani is local and probably is related to the peripheral (? intramural) [sic] nervous plexus" (11). In his textbooks, Kuntz states that peristalsis is coordinated by "myenteric reflexes" transmitted by synaptic connections between enteric neurons $(12,16)$, and that the persistence of sphincteric response accompanying rectal contraction in man after destruction of sacral innervation is evidence that "this reciprocal reaction is mediated through intrinsic reflex mechanisms that are activated by tension on the rectal wall" (12). Our findings demonstrate that myenteric ganglion cells are not essential for this response.

A view that takes exception to the concept of intrinsic reflex transmission was expressed in 1900 by Bayliss and Starling, who, on the basis of mechanical and electrical stimulation of naked nerve endings in dogs and rabbits, concluded that local nervous mechanisms become less important and external innervation more important as either end of the gut was reached (25). Moreover, Garry was able to show in decerebrate and decapitated cats that pudendal nerves were not involved in the internal anal sphincteric reflex, 
whereas the pelvic hypogastric nerves were (26). Learmonth and Markowitz (27) further clarified the functions of these hypogastric nerves as inhibitory to the internal anal sphincter by demonstrating that, after intravenous administration of ergotoxin, electrical stimulation of hypogastric nerves produced relaxation of the sphincter, whereas contraction of the sphincter followed nerve stimulation without previous administration of ergotoxin. This was presumed to be due to the selective effect of ergotoxin in eliminating motor responses without affecting inhibitory responses.

The question then arises as to whether an alternate idiomuscular pathway might not exist. For example. experiments on the urinary bladder have been cited (28) in favor of a myogenic basis for sphincteric relaxation and against the theory of reciprocal innervation. In these studies, smooth muscle sphincters were plastically constructed directly from the detrusor substance. When the detrusor contracted, the "sphincter" actively opened, presumably because of activation by spread of smooth muscle contraction. Our experiments clearly demonstrate that sphincteric opening occurs most frequently without associated rectal or sigmoid contraction, as recorded by this technic (Figure 3, A). Therefore, the response is not necessarily dependent upon spread of smooth muscle contraction for its activation. Furthermore, when peristalsis does appear. the sphincter relaxes at the moment of distension of the rectosigmoid colon before the wave of contraction reaches even the mid-rectum (Figure $3, \mathrm{D})$.

It therefore becomes necessary to account. on a basis other than muscular contraction, for the normal sphincteric relaxation that occurs when myenteric ganglion cells are absent from the sphincter, as in our patients with Hirschsprung's disease. Our studies do not exclude the possibility that inhibition of the internal sphincter follows noncontractile events in rectal smooth muscle, although this mechanism seems unlikely. There is some ultramicroscopic (29) and physiologic (30) evidence that transmission of impulses from muscle fiber to muscle fiber may occur in the absence of neural elements, but there is no indication that this can occur without muscular contraction. Since velocity of conduction in ganglion- free intestinal muscle is 3 to $5 \mathrm{~cm}$ per second (30), an impulse, under conditions of our experiment, would require 5 to 8 seconds to travel $25 \mathrm{~cm}$ from the distending balloon to the sphincter. The immediate sphincteric relaxation with rectosigmoid distension in our studies argues against the applicability of the theory of muscular transmission in this instance. Another possible explanation lies in the demonstration by both chemical and histochemical technics that there is no decrease in the content of either true cholinesterase or pseudocholinesterase in the aganglionic bowel of Hirschsprung's disease (31). These enzymes have been shown to be concentrated in hypertrophied nerve fibers (axons) that are present in normal or increased numbers in the aganglionic segment (31-33). It is possible that the sphincter muscle may be actively fired by acetylcholine derived from naked nerve endings in the absence of ganglion cells.

Recently, a study employing special staining technics for cholinesterase has raised the question of the persistence of a few light-staining ganglion cells in the spastic segment in Hirschsprung's disease. In addition, the outer muscular layer of that segment showed markedly increased staining for cholinesterase (33).

Finally, an investigation of possible sensory pathways for the sphincter reflex was carried out by a study of patients who had had resection of the rectosigmoid colon. Surgical excision of this segment abolished the normal response in all patients. Gaston reported similar findings that led him to conclude that the rectosigmoid colon may serve as part of the afferent limb of a reflex arc extending from rectum to anal sphincter via the spinal cord (34). Further support for this supposition is obtained in the motility pattern noted in our patients who have undergone partial proctosigmoidectomy. In such subjects, distension of the intact rectum produced sphincteric opening, whereas distension above the anastomosis did not. A spinal pathway as the only route for this reflex, however, is effectively ruled out by the evidence adduced by Denny-Brown (11), who demonstrated that a normal reflex exists in humans after destruction of sacral nerve roots by cauda equina lesions and after hypogastric nerve resections. Denny-Brown explained the discrepancy between his human results and those 

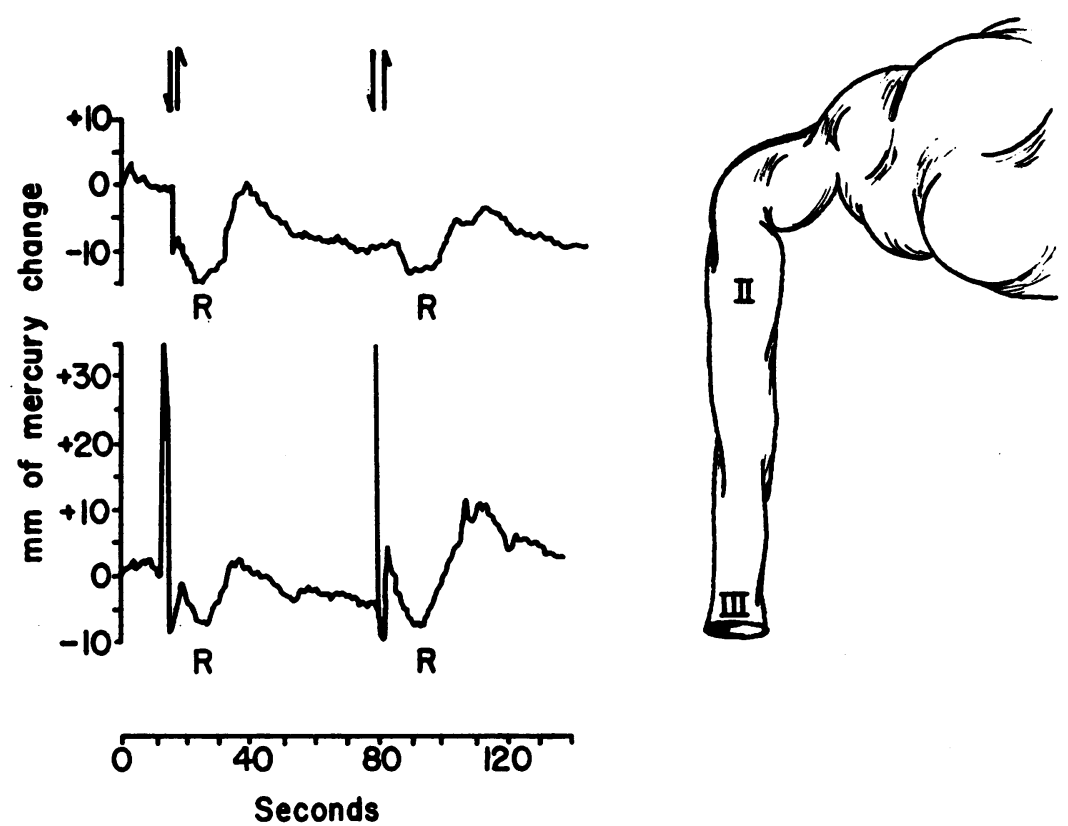

Fig. 8. Simultaneous relaxation (R) of aganglionic Rectum (II) AND INTERNAL ANAL SPHINCTER (III). Rectal balloon lies in spastic aganglionic segment of a patient with Hirschsprung's disease.

reported in decerebrate cats by Garry (26) on the basis of spinal shock in the latter's acute animal experiments. We have also found a normal response in a patient with inferior mesenteric neurectomy. A recently proposed theory, which is particularly intriguing in the light of these facts, holds that enteric contractions are due to a true local reflex with sensory impulses originating in the mucous membranes being transmitted by direct nervous connections between mucosa and muscle coats (35). For obvious reasons, no patients with simple transection of the rectum without resection were available for study of this hypothesis.

Intramural ganglion cells play no role in the afferent limb of the sphincteric reflex, as shown by the existence of a normal response in patients with Hirschsprung's disease studied preoperatively, when the rectum, later proved histologically to be aganglionic, was distended.

The mechanisms by which abnormal repetitive responses are evoked after proctosigmoidectomy remain unexplained. This interesting abnormal response was seen only in patients who demonstrated fecal soiling postoperatively, whereas no response at all could be elicited in patients who were asymptomatic postoperatively. Two in- fants with Hirschsprung's disease were studied before and after proctosigmoidectomy. Both had normal sphincteric responses pre- and abnormal responses postoperatively, at a time when fecal dribbling was prominent. When dribbling later ceased in one of these infants, a follow-up study showed absence of any sphincteric response, indicating that an abnormal sphincteric reflex may be causally related to fecal incontinence in the postoperative cases.

Three patterns were observed in response to distension of the aganglionic segment in Hirschsprung's disease. One, the normal response, consisted in sphincteric relaxation without rectal relaxation. The second was rectal relaxation without sphincteric relaxation. Neither of these two responses was frequent, but a third response, distinctly unexpected and unexplained, was found in every patient with Hirschsprung's disease studied preoperatively, but in only 5 of the remaining 38 patients in the entire study group. This response consisted of relaxation of the aganglionic segment concomitant with sphincteric relaxation (Figure 8). This test, therefore, may be valuable in establishing the diagnosis of aganglionic megacolon.

B. Methodology. A brief discussion seems ap- 
propriate concerning the technic employed for this study. First of all, the internal anal sphincter has been demonstrated to be in a state of constant tonic contraction. This is shown by the pressure rise seen in the caudad balloon as it is withdrawn into the anal sphincteric area (Figure 2). The magnitude of this pressure increase, as well as the pressure fall during relaxation, depends upon the force with which the caudad balloon is held against the sphincter, as well as upon the distance that the balloon penetrates the sphincteric area, provided that the counterweight force is kept constant. This can be accounted for, first, on the simple mechanical basis of increased traction against an unyielding sphincter, and second. by the progressively greater number of circular fibers of sphincteric muscle involved as the balloon is pulled further into the sphincteric area. Recorded pressures, therefore, have only relative significance. When traction was held constant, pressure remained constant at an elevated level. Only when the caudad balloon enters the high pressure zone can the sphincter response be demonstrated (Figure 2), and then only in a very limited segment of the distal rectum, since placement of the caudad balloon could not be varied more than 1 $\mathrm{cm}$ if the sphincteric response were to be elicited. This correlates well with the anatomy of the internal anal sphincter, which has been shown to consist of a firm white band of concentric muscle fibers, a direct continuation of the circular smooth muscle fibers of the rectum $(16,18,36-39)$. Sphincteric relaxation therefore occurs as a result of inhibition of normal sphincter tone when the rectum or rectosigmoid colon is distended. This relaxation is apparently reflex in nature and cannot be inhibited by voluntary effort.

Two of the variables that influenced the magnitude of pressure fall during sphincteric relaxation were the distance that the balloon had penetrated into the sphincter area and the amount of air used to distend the cephalad balloons. As decreasing increments of air were employed for distension. the drop in pressure diminished proportionately until no further sphincteric response occurred. The threshold for this minimal response was 10 to $15 \mathrm{ml}$ of injected air. The establishment of a range, rather than a definite value, for the amount of air needed to produce the response suggested that the response is not an "all-or-none" phenome- non, but rather that either a larger number of sphincteric muscle fibers are called into play with increasing distension of the rectum, or, less likely, that each individual muscle fiber can vary its tonus depending upon the strength of the stimulus.

In our experiments, sigmoid distension (25 to $35 \mathrm{~cm}$ from the anus) proved an effective stimulus for sphincteric relaxation. Gaston, in contrast. found distension above the rectum ineffective (34).

The initial spike deflection (Figure 3, C) that sometimes precedes the pressure drop in the caudad recording balloon is not caused by reflex contraction of the external anal sphincter, which has been reported to occur with distension of the rectum (39), since this spike was seen in paraplegics who had complete paralysis of the external sphincter. It was also recorded in the middle balloon $10 \mathrm{~cm}$ cephalad to the anus. It is therefore evident that the spike cannot result from external sphincteric contraction. We found that, when the distending balloon was kept inflated for varying, generally brief periods, the duration of the spike coincided with that of distension and disappeared rapidly (Figure 9) as the distending balloon was rapidly deflated. It seems likely, therefore, that this spike represents increasing pressure in a closed container (the lower colon) in those patients in whom plastic adaptation of the colon to the balloon was either totally insufficient or too slow to accommodate the increasing intraluminal mass. The passive spike differs from contraction around the distending balloon; the pressure increase seen with contraction persists after the distending balloon is deflated (Figure 3, C). The minute, spontaneous decrease in pressure seen occasionally in the distending balloon before deflation (Figure 9) probably represents early plastic adaptation of the rectum. As might have

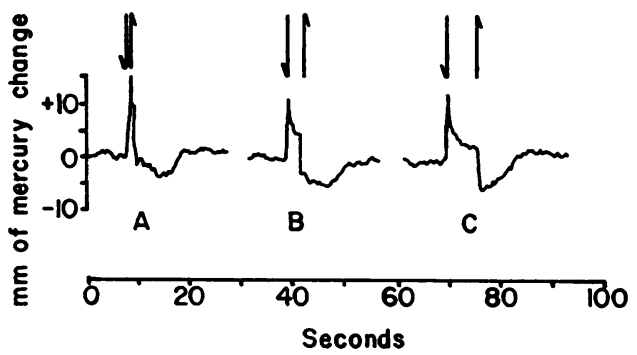

Fig. 9. "SPIKE" of DISTEnsion. The sharp spike of brisk distension (A) is compared with the border spike seen when the distension is prolonged ( $\mathrm{B}$ and $\mathrm{C}$ ). 
been anticipated, the spike of distension was present in all cases of Hirschsprung's disease when the distending balloon lay in the spastic segment.

\section{SUM MARY}

1. An involuntary internal anal sphincteric reflex has been identified by balloon manometric technics. Studies were performed to investigate the normal physiology and neural pathways of this response, and the effect of various pathological states upon it.

2. Evidence is presented by means of these technics to indicate that, while an intact rectosigmoid colon is needed for this response, neither intramural ganglia nor spinal cord connections are required for its mediation; nor does an idiomuscular transmission appear to be involved.

3. Normal sphincteric relaxation was found in unoperated cases of Hirschsprung's disease, indicating that constipation and megacolon in this disorder are not due to an unyielding internal anal sphincter.

4. A correlation is demonstrated between abnormal sphincter response and fecal incontinence after proctosigmoidectomy. A normal response is found in patients who are incontinent on the basis of functional megacolon.

5. The possible application of this test to the diagnosis of Hirschsprung's disease is suggested.

\section{ACKNOWLEDGMENT}

The authors wish to acknowledge with thanks the suggestions and advice of Dr. John Magladery.

\section{REFERENCES}

1. Swenson, O., Rheinlander, H. F., and Diamond, I. Hirschsprung's disease: a new concept of the etiology. New Engl. J. Med. 1949, 241, 551.

2. Davidson, M., Sleisenger, M. H., Almy, T. P., and Levine, S. Z. Studies of distal colonic motility in children, I. Non-propulsive patterns in normal children. Pediatrics 1956, 17, 807.

3. Davidson, M., Sleisenger, M. H., Almy, T. P., and Levine, S. Z. Studies of distal colonic motility in children, II. Propulsive activity in diarrheal states. Pediatrics 1956, 17, 820.

4. Davidson, M., Sleisenger, M. H., Steinberg, H., and Almy, T. P. Studies of distal colonic motility in children, III. The pathologic physiology of congenital megacolon-(Hirschsprung's disease). Gastroenterology 1955, 29, 803.
5. Code, C. F., Wilkinson, G. R., Jr., and Sauer, W. G. Normal and some abnormal colonic motor patterns in man. Ann. N. Y. Acad. Sci. 1954, 58, 317.

6. Chaudhary, N. A., and Truelove, S. C. Colonic motility. A critical review of methods and results. Amer. J. Med. 1961, 31, 86.

7. Chaudhary, N. A., and Truelove, S. C. Human colonic motility: a comparative study of normal subjects, patients with ulcerative colitis, and patients with the irritable colon syndrome, I. Resting patterns of motility. Gastroenterology 1961, 40, 1.

8. Schuster, M. M., Hendrix, T. R., and Mendeloff, A. I. Studies on the internal anal sphincter reflex. Clin. Res. 1961, 9, 155.

9. Gowers, W. R. The automatic action of the sphincter ani. Proc. roy. Soc. 1877, 26, 77.

10. Connell, A. M. The motility of the pelvic colon. I Motility in normals and in patients with asymptomatic duodenal ulcer. Gut 1961, 2, 175.

11. Denny-Brown, D., and Graeme Robertson, E. G. An investigation of the nervous control of defecation. Brain 1935, 58, 256.

12. Kuntz, A. The Autonomic Nervous System, 4th ed. Philadelphia, Lea \& Febiger, 1953, p. 238.

13. Swenson, O. Hirschsprung's disease (aganglionic megacolon). New Engl. J. Med. 1959, 260, 972.

14. Swenson, O., Fisher, J. H., and Scott, J. E. S. Diarrhea following rectosigmoidectomy for Hirschsprung's disease. Surgery 1960, 48, 419.

15. Hiatt, R. B. The pathologic physiology of congenitai megacolon. Ann. Surg. 1951, 133, 313.

16. Kuntz, A. Textbook of Neuroanatomy, 5th ed. Philadelphia, Lea \& Febiger, 1950, p. 442.

17. Bodian, M., Stephens, F. D., and Ward, B. C. H. Hirschsprung's disease. Lancet 1950, 1, 19.

18. Swenson, O., Fisher, J. H., and MacMahon, H. E. Rectal biopsy as an aid in the diagnosis of Hirschsprung's disease. New Engl. J. Med. 1955, 253, 632.

19. Evans, W. A., and Willis, R. Hirschsprung's disease. The roentgen diagnosis in infants. Amer. J. Roentgenol. 1957, 78, 1024.

20. Bodian, M. Fortschritte auf dem Gebiete der Hirschsprungschen Krankheit. Mschr. Kinderh. 1955, 103,135

21. Carter, H. G. Congenital aganglionic megacolon (Hirschsprung's disease). Tex. St. J. Med. 1957, 53, 771.

22. Fisher, J. H., and Swenson, O. Aganglionic lesions of the colon. Amer. J. Surg. 1960, 99, 134.

23. Bodian, M., Carter, C. O., and Ward, B. C. H. Hirschsprung's disease. Lancet 1951, 1, 302.

24. Keefer, G. P., and Mokrohisky, J. F. Congenital megacolon (Hirschsprung's disease). Radiology 1954, 63, 157.

25. Bayliss, S. M., and Starling, E. H. The movements and the innervation of the large intestine. I. The large intestine of the dog. J. Physiol. 1900, 26, 107. 
26. Garry, R. C. The responses to stimulation of the caudal end of the large bowel in the cat. J. Physiol. 1933, 78, 208.

27. Learmonth, J. R., and Markowitz, J. Studies on the function of the lumbar sympathetic outflow. I. The relation of the lumbar sympathetic outflow to the sphincter ani internus. Amer. J. Physiol. 1929, 89, 686.

28. Plum, F. Rhythmic vesical activity-its origin and relationship to normal micturition. Trans. Amer. neurol. Ass. 1959, 126.

29. Dewey, M. M., and Barr, L. Intercellular connection between smooth muscle cells: the nexus. Science 1962, 137, 670.

30. Prosser, C. L., and Sperelakis, N. Transmission in ganglion-free circular muscle from the cat intestine. Amer. J. Physiol. 1956, 187, 536.

31. Adams, C. W. M., Marples, E. A., and Trounce, J. R. Achalasia of the cardia and Hirschsprung's disease. The amount and distribution of cholinesterases. Clin. Sci. 1960, 19, 473.

32. Kamijo, K., Hiatt, R. B., and Koelle, G. B. Congenital megacolon. A comparison of the spastic and hypertrophied segments with respect to the cholinesterase activities and sensitivities to acetylocholine, DFP and the barium ion. Gastroenterology 1953, 24, 173.

33. Neimi, M., Kouvalainen, K., and Hjelt, L. Cholinesterases and monoamine oxidase in congenital megacolon. J. Path. Bact. 1961, 82, 363.

34. Gaston, E. A. Physiological basis for preservation of fecal continence after resection of rectum. J. Amer. med. Ass. 1951, 146, 1486.

35. Bülbring, E., Lin, R. C. Y., and Schofield, G. An investigation of the peristaltic reflex in relation to anatomical observations. Quart. J. exp. Physiol. 1958, 43, 26.

36. Stonesifer, G. L., Jr., Murphy, G. P., and Lombardo, C. R. The anatomy of the anorectum. Amer. J. Surg. 1960, 100, 666.

37. Gorsch, R. V. Proctologic Anatomy. Baltimore, Williams \& Wilkins, 1955, p. 67.

38. Gorsch, R. V. The sigmoid, rectum and anal canal. Clin. Sympos. (CIBA) 1960, 12, 35.

39. Gaston, E. A. Fecal continence following resections of various portions of the rectum with preservation of the anal sphincters. Surg. Gynec. Obstet. 1948, 87, 669 . 